\title{
EG-1 interacts with c-Src and activates its signaling pathway
}

\author{
MING LU, LIPING ZHANG, MARYAM R. SARTIPPOUR, ANDREW J. NORRIS and MAI N. BROOKS \\ Department of Surgery, Division of Oncology, UCLA School of Medicine, Los Angeles, CA, USA
}

Received March 27, 2006; Accepted May 17, 2006

\begin{abstract}
EG-1 is significantly elevated in breast, colorectal, and prostate cancers. Overexpression of EG-1 stimulates cellular proliferation, and targeted inhibition blocks mouse xenograft tumor growth. To further clarify the function of EG-1, we investigated its role in c-Src activation. We observed that EG-1 overexpression results in activation of c-Src, but found no evidence that EG-1 is a direct Src substrate. EG-1 also binds to other members of the Src family. Furthermore, EG-1 shows interaction with multiple other SH3- and WWcontaining molecules involved in various signaling pathways. These observations suggest that EG-1 may be involved in signaling pathways including c-Src activation.
\end{abstract}

\section{Introduction}

Cancer is a major cause of morbidity, and the second leading cause of death in the American population. Several major oncogenes and tumor suppressor genes have been identified to contribute to the neoplastic transformation of epithelial cells. These include c-Src, p53, c-myc, ras, Rb (retinoblastoma), BRCA-1 and -2 (breast cancer susceptibility genes), Her-2, cyclin D1, and PTEN (phosphatase and tensin homolog) (1).

We previously discovered a novel gene EG-1 that is induced in endothelial cells by tumor conditioned media (endothelial derived gene-1) (2). In addition to its expected presence in the endothelial cells of blood vessels, EG-1 expression is significantly elevated in cancer cells from several types of adenocarcinomas including breast, colorectal and prostate (3). We reported that overexpression of EG-1 stimulates cellular proliferation in vitro and increases xenograft size in vivo (4). In subsequent study, we have observed that EG-1 targeted inhibition significantly blocks human breast cancer cell proliferation in vitro and xenograft growth in mice (unpublished data). A key to the understanding of cellular signal transduction pathways is to determine whether certain proteins of interest interact with one another. Protein-protein interactions are often mediated by non-catalytic and conserved domains (5). The presence of an N-terminal poly-proline

Correspondence to: Dr Mai N. Brooks, UCLA, Box 951782, Los Angeles, CA 90095, USA

E-mail: maibrooks@mednet.ucla.edu

Key words: EG-1, magicin, Med28, Src, SH3, WW domain, cancer region in the EG-1 sequence suggests that EG-1 might interact with SH3 (Src homology) and WW domains (6). This led us to screen EG-1 for binding to a large panel of SH3 and WW containing proteins, where we repeatedly observed an association between EG-1 and c-Src (cellular Rous Sarcoma viral oncogene).

\section{Materials and methods}

Cell culture. Human embryonic kidney HEK-293 cells were purchased from American Tissue Type Culture Collection (ATCC, Rockville, MD). The cells were maintained in Dulbecco's minimal essential medium (DMEM, Invitrogen, Carlsbad, CA) with $10 \%$ heat-inactivated FCS (fetal calf serum), 100,000 units/l penicillin, and $100 \mathrm{mg} / \mathrm{l}$ streptomycin, at $37^{\circ} \mathrm{C}$ in $5 \% \mathrm{CO}_{2}$.

Domain binding assay. Domain array assays were obtained from Panomics (Redwood City, CA). Four SH3-containing protein blots (TranSignal ${ }^{\mathrm{TM}} \mathrm{SH} 3$ ) and two WW-containing protein blots (TranSignal WW) were used following the manufacturer's protocol. Briefly, histidine tagged EG-1 was overexpressed in HEK-293 cells by transient transfection. Then, EG-1 protein was affinity purified and incubated with SH3 or WW Domain Array membranes with gentle shaking for $2 \mathrm{~h}$ at room temperature. After incubation, the membranes were washed three times with wash buffer for $10 \mathrm{~min}$ each at room temperature. We then incubated the membrane with anti-histidine HRP conjugate for $1 \mathrm{~h}$ at room temperature. The membranes were washed three times again as above and visualized with HRP-based chemiluminescence detection. The blots were scanned and density was measured with Scion Image software (Scion Corp., Frederick, MD).

Transfection. We used the pcDNA3.1D/V5-His-TOPO vectors (Invitrogen) and pShuttle-IRES-hrGFP-1 (Stratagene, La Jolla, CA) vectors to carry the full-length human EG-1 gene, according to the manufacturer's instructions. Empty vectors were used as negative controls. Specifically, standard lipofectamine (Invitrogen) was utilized for obtaining transient transfectants according to the manufacturer's protocol. Expression of the EG-1 gene was confirmed by Western blot analyses. Twenty-four hours after transfection, cell lysates were harvested and subjected to IP (immunoprecipitation) or IB (immunoblotting).

Generation of antibodies. Polyclonal antibodies that recognize a specific peptide epitope on human EG-1 were generated by 
Table I. EG-1 binds to SH3 (A) and WW (B) domains of many proteins.

\begin{tabular}{|c|c|c|}
\hline $\begin{array}{l}\text { A, } \\
\text { Gene }\end{array}$ & Full name of gene & Fold \\
\hline Tec & Tyrosine-protein kinase Tec & 5.3 \\
\hline Yes1 & Yamaguchi sarcoma virus oncogene homolog 1 & 4.8 \\
\hline c-Src & Cellular Rous Sarcoma viral oncogene homolog & 4.5 \\
\hline OSF & Osteoclast stimulating factor 1 & 4.3 \\
\hline BTK & Bruton tyrosine kinase & 3.9 \\
\hline SLK & Proto-oncogene tyrosine protein kinase FYN & 3.9 \\
\hline ABL2 & Abelson-related protein; Arg & 3.8 \\
\hline PIG2 & 1-phosphatidylinositol-4,5-bisphosphate phosphodiesterase $\gamma 2$ & 3.8 \\
\hline SNX9 & Sorting nexin 9 & 3.4 \\
\hline NPH1 & Juvenile nephronophthisis 1 protein & 2.8 \\
\hline PSTPIP1 & Proline-serine-threonine phosphatase interacting protein 1; CD2 tail-binding protein & 2.7 \\
\hline DFKZp434D-D4 & Similar to hypothetical protein; Domain no. 4 & 2.7 \\
\hline Stam & Signal transducing adaptor molecule & 2.6 \\
\hline PI3ß & Phosphoinositide-3-kinase regulatory $ß$ subunit & 2.6 \\
\hline PI3 $\alpha$ & Phosphatidylinositol 3-kinase regulatory $\alpha$ subunit & 2.6 \\
\hline Tim & Rho guanine nucleotide exchange factor (GEF) 5 & 2.5 \\
\hline KIAA0418-D4 & KIAA0418 gene product; likely ortholog of five SH3 domains; Domain no. 4 & 2.5 \\
\hline KIAA0790 & KIAA0790 protein & 2.5 \\
\hline PSD95 & Presynaptic density protein 95 & 2.5 \\
\hline Hck & Hemopoietic cell kinase & 2.5 \\
\hline NEBL & Nebulette & 2.5 \\
\hline
\end{tabular}

$\mathrm{B}$, Gene Full name of gene Fold

MAGI-3-D1 Membrane-associated guanylate kinase-related MAGI-3, WW Domain no. 1

TAZ Transcriptional co-activator with PDZ-binding motif (TAZ) 4.5

NEDD4L-D2 NEDD4-like ubiquitin ligase 3, WW Domain no. 2

MAGI-3-D2 Membrane-associated guanylate kinase-related MAGI-3, WW Domain no. 2

YAP1 Yes-associated protein 1,65 kDa (YAP65) 3.2

NEDD4-D3 Ubiquitin-protein ligase Nedd-4, WW Domain no. 3

Quality Controlled Biochemicals (QCB, Hopkinton, MA). Pre-immune and immune sera were harvested. Polyclonal antibodies were also affinity purified. For Western analysis, the secondary antibody used was horseradish peroxidaseconjugated monoclonal anti-rabbit IgG (cat. A1949, gammachain specific, Sigma). Antibodies to c-Src and Yes were purchased from Cell Signaling (Beverly, MA).

Western blot analysis. Cell pellets were lysed in preheated $0.025 \mathrm{~mol} / \mathrm{l}$ Tris (pH 7.4), $0.001 \mathrm{~mol} / \mathrm{l}$ EDTA, and 0.3\% SDS, and then boiled for $5 \mathrm{~min}$. The cell lysate was centrifuged at $12,000 \mathrm{x} \mathrm{g}$ for $10 \mathrm{~min}$, and the supernatant was saved. Protein concentration was measured by the Bradford assay (Bio-Rad, Hercules, CA). For Western blot analysis, $\sim 40 \mu \mathrm{g}$ of protein was separated by a $12 \%$ SDS-PAGE gel, and transferred to a nitrocellulose membrane by electrophoretic blotting. The membrane was blocked overnight $\left(4^{\circ} \mathrm{C}\right)$ with $5 \%$ non-fat dry milk in TBST (Tris-buffered saline, $0.1 \%$ Tween-20), and then incubated with a 1:500 dilution of primary antibody for $2 \mathrm{~h}$. The blots were then washed three times over $30 \mathrm{~min}$ in TBST, and incubated for $1 \mathrm{~h}$ with horseradish peroxidase-conjugated secondary antibody mouse anti-rabbit $\operatorname{IgG}(1: 10,000)$, and then washed in TBS-Tween as before. The membranes were then developed using the Supersignal West Pico Chemiluminescent Western blotting detection system according to the manufacturer's instructions (Pierce, Arlington Heights, IL). Ponceau $\mathrm{S}$ staining was performed to demonstrate equal loading.

Immunoprecipitation. Cell lysates were pre-incubated solely with protein A/G Plus-Agarose (Santa Cruz Biotechnology, Santa Cruz, CA) at $4^{\circ} \mathrm{C}$ for $1 \mathrm{~h}$, then the mixture was centrifuged at $3,000 \mathrm{x}$ g for $5 \mathrm{~min}$ to pellet these beads and any non-specific interacting proteins. One mg of supernatant protein was incubated with anti-c-Src or anti-Yes antibody and $30 \mu \mathrm{l}$ 


\section{SH3 domain}

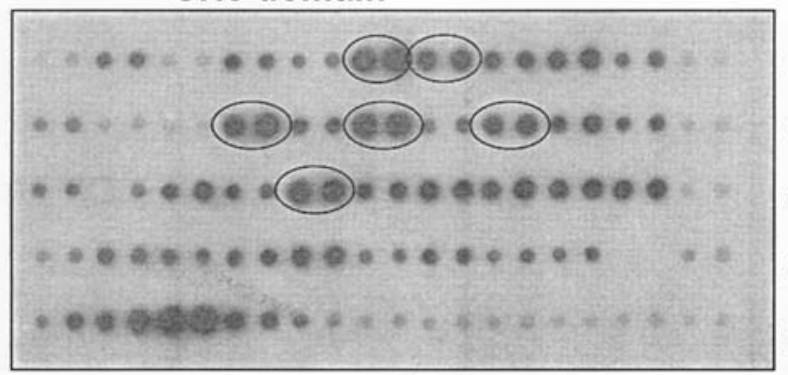

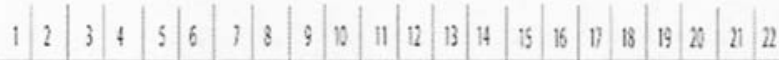

\begin{tabular}{|c|c|c|c|c|c|c|c|c|c|c|}
\hline A Anctiphss & $a$ & SYY & Constin & $N=0$ & & & SAth & th & $(6<0) ?$ & $\infty$ \\
\hline $\mathrm{dg} 2$ & ED:55 & fit & & Nekin & & & & What & W:20: & $\omega s$ \\
\hline$W A D$ & 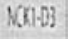 & Y124 & 170 & & $k 60^{2}$ & $\mathrm{XOSS}$ & In & His & $\operatorname{sen}$ & WS \\
\hline 63 & $|B|$ & BS? & 52 & [3) & $17 \% 21$ & 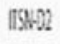 & ISI & 困 & & $\omega:$ \\
\hline pos & $p m$ & $c s$ & $\infty$ & $c 00$ & $p x$ & PS & oss & $\alpha s$ & $m$ & $\omega$ \\
\hline
\end{tabular}

Figure 1. EG-1 binds to SH3 domains of many proteins. One representative of blots is shown.

of protein $\mathrm{A} / \mathrm{G}$ Plus-Agarose overnight at $4^{\circ} \mathrm{C}$ under agitation, and $1 \mathrm{mg}$ of proteins from the same source was incubated with normal rabbit or mouse IgG (Santa Cruz Biotechnology) and protein A/G- Plus-Agarose (for negative controls). After incubation, immunocomplexes were pelleted by centrifugation at $3,000 \mathrm{x} \mathrm{g}$ for $5 \mathrm{~min}$ at $4^{\circ} \mathrm{C}$. The pellets were then resuspended and washed three additional times with immunoprecipitation buffer to remove nonspecific interactions. Laemmli loading buffer was then added to the beads. After boiling, the proteins were separated by $12 \%$ SDS-PAGE and analyzed by Western blotting.

In vitro kinase assay. EG-1 was synthesized by $\mathrm{TNT}^{\circledR} \mathrm{T} 7$ Coupled Reticulocyte Lysate System (RLS, Promega, Madison, WI) following the manufacturer's protocol, or immunoprecipitated from EG-1 overexpressed HEK-293 cells (4). The EG-1 purified by immunoprecipitation was washed once in TBS to remove detergents. Each pellet was suspended in reaction buffer $(5 \mu 1100 \mathrm{mM} \mathrm{MnCl} 2,1.25 \mu 11 \mathrm{M}$ HEPES, $\mathrm{pH} 7.3,0.25 \mu 1100 \mathrm{mM}$ sodium orthovanadate). $\gamma^{-32} \mathrm{P}(10 \mu \mathrm{Ci})$ was added and incubated at $25^{\circ} \mathrm{C}$ for $45 \mathrm{~min}$. To terminate the kinase reaction, we added $15 \mu 1$ of Laemmli sample buffer. The samples were boiled for $5 \mathrm{~min}$, then proteins were resolved by $10 \%$ SDS-PAGE gel. The gel was dried and exposed to X-ray film for varying lengths of time.

\section{Results}

EG-1 interacts with many SH3 and WW domain proteins. We screened 150 proteins with SH3 domains and 67 proteins with WW domains. To compare the relative interactions of these SH3 and WW domain proteins with recombinant EG-1, the blots were scanned and quantitated. Table IA lists those SH3 domain proteins that have at least 2.5-fold binding with EG-1 in comparison with negative control, which is measured by the interaction of EG-1 with GST (glutathione S-transferase). We repeatedly observed an association between EG-1 and c-Src (Fig. 1). Other than c-Src, the following exhibited the most binding with EG-1: Yes1 (Yamaguchi sarcoma virus oncogene homolog 1), Tec (tyrosine protein kinase Tec), OSF (osteoclast stimulating factor), BTK (Bruton tyrosine kinase), SLK (proto-oncogene tyrosine protein kinase FYN), ABL2 (Abelson-related protein), and PIG2 (1-phosphatidylinositol4,5-bisphosphate phosphodiesterase $\gamma 2$ ). For WW domains, EG-1 appears to interact with MAGI-3 (membrane-associated guanylate kinase inverted-3) and NEED4 (neural precursor cell expressed, developmentally down-regulated 4)-like ubiquitin ligase 3 (Table IB). The negative control is measured by the interaction of EG-1 with GST (glutathione S-transferase).

EG-1 interacts with $c$-Src and Yes. Several different polyclonal antibodies against various EG-1 peptide fragments were made. We found that peptides no. 34-53 (PGAPRPSSSTLVDELES SFE) reliably generated antibodies well suited for Western blot analysis. The sequence for this epitope is unique, as determined by searches in the Genbank database.

To study EG-1-src binding in living mammalian cells, we transiently transfected HEK-293 cells with EG-1 plasmid or with vector alone (Fig. 2A). Lane 1 (EV) shows that HEK-293 cells express EG-1 and c-Src. Transfection with EG-1 plasmid increases EG-1 without affecting the c-Src level (lane 2, panels 1 and 3). Immunoprecipitation of cell lysates with anti-Src antibody, followed by immunoblotting with anti-EG-1 antibody demonstrated that EG-1 interacts with c-Src (panel 5). Furthermore, EG-1 overexpression resulted in a higher proportion of c-Src proteins that are bound to EG-1. Similarly, we validated the interaction between EG-1 and Yes protein as seen in Fig. 2B. As with EG-1-Src complexes, we found that EG-1 interacts with endogenous Yes and that this binding is similarly enhanced in cells overexpressing EG-1.

EG-1 is not a substrate of c-Src. We next investigated whether EG-1 is a natural substrate of c-Src kinase. in vitro kinase assay showed that c-Src does not phosphorylate EG-1 (Fig. 3). The accuracy of the kinase assay system was ensured by introducing a natural c-Src substrate STAT (signal transducer and activator of transcription) (7) to the system (lane 5). STAT was phosphorylated, indicating that the system worked well. c-Src did not phosphorylate EG-1 synthesized by the Reticulocyte Lysate system (lane 2) nor EG-1 synthesized by HEK-293 cells following affinity purification (lane 4).

EG-1 overexpression is involved in the activation of c-Src. We investigated whether overexpression of EG-1 is related with the activation of c-Src. HEK-293 cells were transiently transfected with empty vector or EG1. EG-1 overexpression did not change the protein level of total c-Src (Fig. 4, panel 1). However, EG-1 overexpression is tightly related with an activated status of c-Src, as manifested by decreased levels of inactive non-p-Tyr419 c-Src (panel 3) and increased active 
$\mathbf{A}$

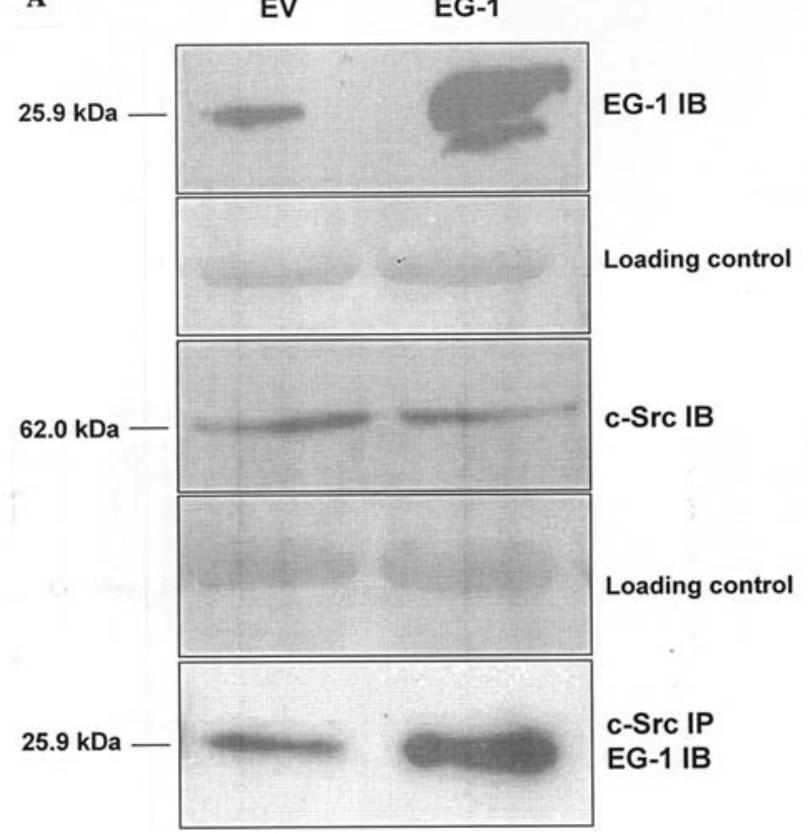

B

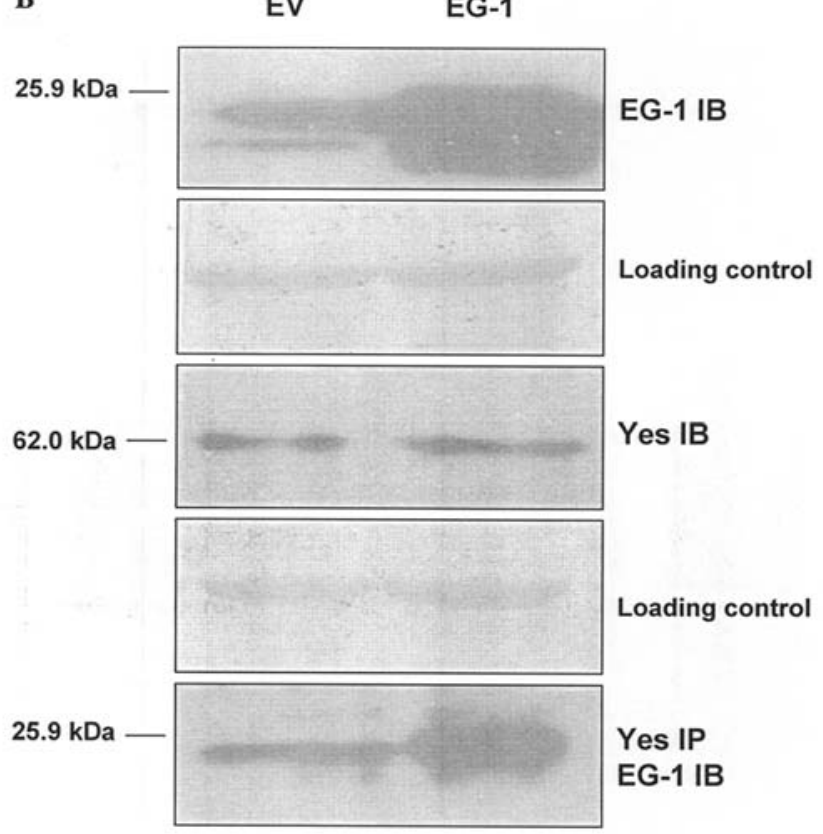

Figure 2. EG-1 binds c-Src (A) and Yes (B). HEK-293 cells were transiently transfected with empty vector (EV) or EG-1. Twenty-four hours after transfection, cell lysates were harvested and subjected to IP (immunoprecipitation) or IB (immunoblotting). Ponceau S staining was performed to demonstrate equal loading.

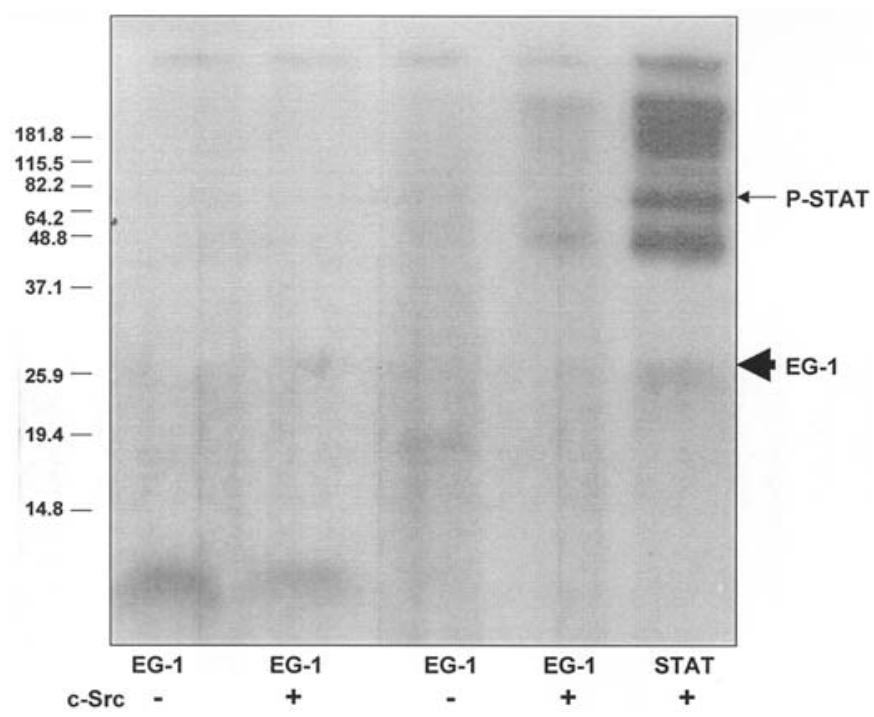

Figure 3. EG-1 is not a substrate of c-Src in in vitro kinase assay. Lane 1, EG-1 synthesized by RLS (Reticulocyte Lysate System) + [ $\left.{ }^{32} \mathrm{P}\right]-\mathrm{ATP}$, without c-Src. Lane 2, EG-1 synthesized by RLS $+\left[{ }^{32} \mathrm{P}\right]-\mathrm{ATP}+$ active c-Src. Lane 3, EG-1 purified from HEK-293 cells + $\left[{ }^{32} \mathrm{P}\right]-\mathrm{ATP}$, without c-Src. Lane 4, EG-1 purified from HEK-293 cells + [ $\left.{ }^{32} \mathrm{P}\right]-\mathrm{ATP}+$ active c-Src. Lane 5, natural c-Src substrate STAT $+\left[{ }^{32} \mathrm{P}\right]-\mathrm{ATP}+$ active $\mathrm{c}-\mathrm{Src}$. This lane serves as positive control of the kinase assay system.

non-p-Tyr530 c-Src (panel 9). EG-1 overexpression after transfection was confirmed by Western blotting (panel 7).

\section{Discussion}

In the present study, we observed that EG-1 overexpression results in c-Src activation. However, EG-1 was not a direct substrate of c-Src, nor did it increase c-Src expression. We also demonstrated that EG-1 binds to the Src family of protein tyrosine kinases c-Src and Yes, and possibly FYN and Hck (Hemopoietic cell kinase, Table IA). EG-1 overexpression was correlated with activation of c-Src. These observations collectively support the hypothesis that the novel gene EG-1 forms a protein-protein complex with $\mathrm{c}-\mathrm{Src}$, which then becomes catalytically active.

c-Src is a member of the Src family of cytoplasmic tyrosine kinases that regulate cell growth, differentiation, cell shape, migration and survival (8). c-Src has been reported to be overexpressed and to play a role in human carcinomas of the breast, colon, and others (9). Src family tyrosine kinases are often activated by receptor tyrosine kinases, such as EGF-R (epidermal growth factor receptor) or PDGF-R (platelet derived growth factor receptor) (10). The mechanisms of c-Src regulation are complex (11). The SH1 kinase domain contains the autophosphorylation site Tyr419 required for activation. The $\mathrm{C}$ terminus contains the Tyr530 which inactivates c-Src when phosphorylated, resulting in a closed configuration. Thus, in the cell, c-Src can be regulated by various kinases and phosphatases. Multiple receptor tyrosine kinases, Gprotein-coupled receptors, FAK (focal adhesion kinase) and adhesion/cytoskeleton molecules can also participate (8). Other regulatory processes include ubiquitylation, mutations, and nitric oxide signaling (12). Certain SH3 binding agents, such as the HIV Nef protein, may also activate c-Src (13). Data derived from our study shows that EG-1 may be added as another c-Src activator.

As a result of EG-1 binding, c-Src presumably phosphorylates the MAPK pathway which has been shown to be crucial in promoting cellular proliferation and is situated downstream from c-Src (14). Previously, we had shown that the phosphorylated active forms of p44/42 MAP kinase, JNK (Jun-terminal kinase) and p38 kinase are elevated in EG-1 

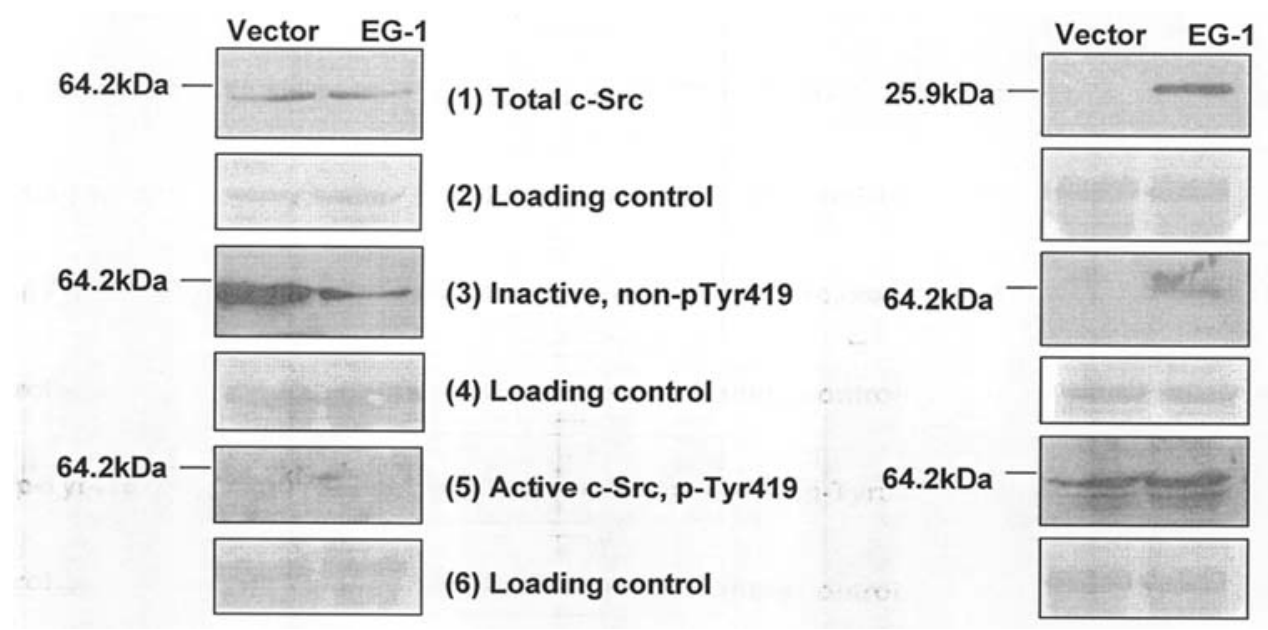

(7) EG-1

(8) Loading control

(9) Active c-Src, non-pTyr530

(10) Loading control

(11) Inactive, p-Tyr530

(12) Loading control

Figure 4. EG-1 activates c-Src. HEK-293 cells were transiently transfected with empty vector (EV) or EG-1. Whole cell lysates were collected and subjected to Western analysis. Ponceau S staining was performed to demonstrate equal loading.

transfected cells (4). During our work on EG-1, we became aware of two recent and unrelated publications on proteins with identical sequences to EG-1. In one publication, the Ramesh group from Harvard called this protein Magicin for Merlin and Grb2 interacting cytoskeletal protein (15). Magicin is described to associate with the actin cytoskeleton, and is proposed to have a role in receptor-mediator signaling at the cell surface. Via affinity binding, blot overlay and coimmunoprecipitation assays, the Ramesh group demonstrated that magicin binds directly to Grb2 (growth factor receptor bound 2 protein). Our SH3 panels contained one entry for each of the two SH3 binding domain fragments of Grb2, which revealed individual weak binding with EG-1 (data not shown). This is consistent with the group Ramesh' observation that full-length Grb2 displayed the strongest binding to EG-1/magicin. Our finding of EG-1's effects on the MAPK pathway may also be explained via its direct interaction with Grb2 (16). A second publication reported that the EG-1 protein product also functions as a member of the Mediator, a multiprotein transcriptional coactivator that is expressed ubiquitously in eukaryotes for induction of RNA polymerase II transcription by DNA binding transcription factors (17). As Med28, it is one subunit of the 'adaptor' that bridges RNA polymerase II with its DNA binding regulatory proteins and transduces both positive and negative signals (18). Anatomically, this is consistent with our previous report that EG-1 was present on immunohistochemical studies in the nucleus as well as in the cytoplasm (3).

In conclusion, it appears thus far that EG-1 is an important protein that has multiple interactions with crucial cellular pathways, such as Src, other tyrosine kinases (Tec, BTK), and the oncogene ABL (19). Overexpression of EG-1 induces key signaling pathways involved in cellular proliferation, an important component of the malignant phenotype. Our findings suggest that EG-1 may be an important target in the design of novel therapy against cancer.

\section{Acknowledgments}

We thank Dr Timothy Lane for his assistance. MNB was supported by a grant from the DOD.

\section{References}

1. Wood WC, Muss HB, Solin LJ and Olopade OI: Malignant tumors of the breast. In: Cancer: Principles and Practice of Oncology. De Vita VT, Hellman S and Rosenberg SA (eds). Lippincott-Raven, Philadelphia, pp1415-1477, 2005.

2. Liu C, Zhang L, Beatty P, Sartippour M, Lane T, Barsky SH, Livingston $\mathrm{E}$ and Nguyen M: Identification of a novel endothelialderived gene. Biochem Biophys Res Commun 290: 602-612, 2002.

3. Zhang L, Maul RS, Rao J, Apple S, Seligson D, Sartippour M, Rubio R and Brooks MN: Expression pattern of the novel gene EG-1 in cancer. Clin Cancer Res 10: 3504-3508, 2004.

4. Lu M, Zhang L, Maul RS, Sartippour MR, Norris A, Whitelegge J, Rao J and Brooks MN: The novel gene EG-1 stimulates cellular proliferation. Cancer Res 65: 6159-6166, 2005.

5. Pawson T: Protein modules and signalling networks. Nature 373: 573-580, 1995

6. Macias MJ, Wiesner S and Sudol M: WW and SH3 domains, two different scaffolds to recognize proline-rich ligands. FEBS Lett 513: 30-37, 2002.

7. Silva CM: Role of STATs as downstream signal transducers in Src family kinase-mediated tumorigenesis. Oncogene 23: 8017-8023, 2004.

8. Parsons SJ and Parsons JT: Src family kinases, key regulators of signal transduction. Oncogene 23: 7906-7909, 2004.

9. Ishizawar RC, Tice DA, Karaoli T and Parsons SJ: The C terminus of c-Src inhibits breast tumor cell growth by a kinaseindependent mechanism. J Biol Chem 279: 23773-23781, 2004.

10. Bromann PA, Korkaya $\mathrm{H}$ and Courtneidge SA: The interplay between Src family kinases and receptor tyrosine kinases. Oncogene 23: 7957-7968, 2004.

11. Yeatman TJ: A renaissance for src. Nature Rev 4: 470-480, 2004.

12. Akhand AA, Pu M, Senga T, Kato M, Suzuki H, Miyata T, Hamaguchi M and Nakashima I: Nitric oxide controls src kinase activity through a sulfhydryl group modification-mediated Tyr-527-independent and Tyr-416-linked mechanism. J Biol Chem 274: 25821-25826, 1999.

13. He JC, Husain M, Sunamoto M, D'Agati VD, Klotman ME, Iyengar R and Klotman PE: Nef stimulates proliferation of glomerular podocytes through activation of Src-dependent Stat3 and MAPK1,2 pathways. J Clin Invest 114: 643-651, 2004.

14. Johnson GL and Lapadat R: Mitogen-activated protein kinase pathways mediated by ERK, JNK, and p38 protein kinases. Science 298: 1911-1912, 2002.

15. Wiederhold T, Lee MF, James M, Neujahr R, Smith N, Murthy A, Hartwig J, Gusella JF and Ramesh V: Magicin, a novel cytoskeletal protein associates with the NF2 tumor suppressor merlin and Grb2. Oncogene 23: 8815-8825, 2004. 
16. Schlessinger J: Common and distinct elements in cellular signaling via EGF and FGF receptors. Science 306: 1506-1507, 2004.

17. Sato S, Tomomori-Sato C, Parmely TJ, Florens L, Zybailov B, Swanson SK, Banks CAS, Jin J, Cai Y, Washburn MP, Conaway JW and Conaway RC: A set of consensus mammalian mediator subunits identified by multidimentional protein identification technology. Mol Cell 14: 685-691, 2004.
18. Conaway JW, Florens L, Sato S, Tomomori-Sato C, Parmely TJ, Yao T, Swanson SK, Banks CAS, Washburn MP and Conaway RC: The mammalian Mediator comples. FEBS Lett 579: 904-908, 2005.

19. Kharas MG and Fruman DA: ABL oncogenes and phosphoinositide-3-kinase: Mechanism of activation and downstream effectors. Cancer Res 65: 2047-2053, 2005. 